\title{
“Vou para casa. E agora?” A difícil arte do Método Canguru no domicílio*
}

"I'm going home. And now?" The difficult art of the Kangaroo Method at home

Me voy a mi casa ¿Y ahora qué pasa? El difícil arte del Método Canguro en el domicilio

\section{Mayara Carolina Cañedo ${ }^{\mathrm{I}}$, Cristina Brandt Nunes ${ }^{\mathrm{II}}$, Maria Aparecida Munhoz Gaiva ${ }^{\mathrm{III}}$, Ana Cláudia Garcia Vieira $^{\mathrm{IV}}$, Iluska Lopes Schultz ${ }^{\mathrm{V}}$}

\begin{abstract}
Resumo: Objetivo: conhecer a experiência dos pais na aplicação do Método Canguru no domicílio. Método: pesquisa qualitativa cujos dados foram obtidos entre março e dezembro de 2016, por meio de entrevistas com 12 mães e três pais de recém-nascidos pré-termos e/ou baixo peso, participantes da terceira etapa do Método Canguru, que foram submetidas à técnica de análise de conteúdo temática. Resultados: os pais mantiveram a posição canguru no domicílio. Apesar de cada família desenvolvê-la de forma diferente, não deixaram de realizá-la. Também conseguiram adaptar-se à nova rotina de cuidados com a chegada do filho em casa e relataram satisfação com as consultas da terceira etapa e de seguimento realizadas no hospital. Conclusão: os pais, mesmo diante dos desafios diários com os cuidados no domicílio, detêm uma significação clara sobre a importância da Posição Canguru para os recém-nascidos pré-termos e/ou baixo peso e sua capacidade de impactar na qualidade do cuidado oferecido.
\end{abstract}

Descritores: Recém-nascido de baixo peso; Recém-nascido prematuro; Enfermagem; Método Canguru; Relações pais-filho

\begin{abstract}
Objective: to get to know the parents' experience in applying the Kangaroo Mother Care at home. Method: qualitative research with data obtained between March and December 2016, by means of interviews with 12 mothers and three fathers of preterm and/or low-birth-weight newborns, participants in the third stage of the Kangaroo Method. The interviews were submitted to thematic content analysis technique. Results: the parents maintained the kangaroo position at home. Although each family developed it differently, they have not failed to implement it. They were also able to adapt to the new care routine with the arrival of the child at home and reported satisfaction with the medical appointments of the third stage and the follow-up carried out at the hospital. Conclusion: the parents, despite the daily challenges with home care, have a clear meaning about the importance of the Kangaroo Position for preterm and / or low-birth-weight newborns and its ability to affect the quality of care offered.
\end{abstract}

Descriptors: Low birth weight infant; Pre-term infant; Nursing; Kangaroo-mother care method; Parent-child relations

\footnotetext{
${ }^{\text {I }}$ Enfermeira, Mestrado em Enfermagem pela Universidade Federal de Mato Grosso do Sul, Hospital Regional de Mato Grosso do Sul. Campo Grande, MS, Brasil. E-mail: maycarolina@hotmail.com Orcid: https://orcid.org/0000-0002-7232-1431.

II Enfermeira, Doutorado em Ciências pela Universidade Federal de São Paulo, Universidade Federal de Mato Grosso do Sul (aposentada). Campo Grande, MS, Brasil. E-mail: cbrandt@terra.com.br Orcid: https://orcid.org/0000-0003-2411-0717

III Enfermeira, Doutorado em Enfermagem em Saúde Pública pela Universidade de São Paulo, Universidade Federal de Mato Grosso. Cuiabá, MT, Brasil. E-mail: mamgaiva@yahoo.com.br Orcid: https://orcid.org/0000-0002-8666-9738

IV Enfermeira, Pós-doutorado na University of Ottawa Faculty of Health Science and School of Nursing, Universidade Federal de Pelotas. Pelotas, RS, Brasil. E-mail: cadicha10@gmail.com Orcid: https://orcid.org/0000-0003-4982-6148

V Enfermeira, Mestrado em Enfermagem pela Universidade Federal de Mato Grosso do Sul, Prefeitura Municipal de Corumbá. Corumbá, MS, Brasil. Email: ilulschultz@gmail.com Orcid: https://orcid.org/0000-0002-2212-2186

"Extraído da dissertação de mestrado: "Método Canguru: a experiência dos pais de recém-nascidos com baixo peso", Programa de Pós-Graduação em Enfermagem, da Universidade Federal de Mato Grosso do Sul, 2017.
} 
Resumen: Objetivo: conocer la experiencia de los padres durante la puesta en práctica del Método Canguro en el domicilio. Método: investigación cualitativa cuyos datos se obtuvieron entre marzo y diciembre de 2016, por medio de entrevistas con 12 madres y tres padres de recién nacidos pretérminos y/o bajo peso, participantes de la tercera etapa del Método Canguro, que se sometieron a la técnica de análisis de contenido temático. Resultados: los padres mantuvieron la posición canguro en el domicilio. Aunque cada familia la haya desarrollado de forma diferente, no dejaron de realizarla. También lograron adaptarse a la nueva rutina de cuidados con la llegada del hijo a casa y relataron satisfacción con las consultas de la tercera etapa y de seguimiento realizadas en el hospital. Conclusión: los padres, aunque estén ante los desafíos diarios con los cuidados en el domicilio, detienen una preocupación clara sobre la importancia de la Posición Canguro para los recién nacidos pretérminos y/o bajo peso y su capacidad de afectar la calidad del cuidado ofrecido.

Descriptores: Recién nacido de bajo peso; Recién nacido prematuro; Enfermería; Método madre-canguro; Relaciones padres-hijo

\section{Introdução}

Apesar dos esforços para a implementação de uma assistência neonatal humanizada, centrada na família e na utilização de estratégias, como o Método Canguru (MC), estudos apontam que as famílias de recém-nascidos pré-termos e/ou baixo peso (RNPTBP) ainda enfrentam dificuldades, tais como: falta de empoderamento e apoio emocional, pouca participação na tomada de decisão e papel secundário dos pais no cuidado. ${ }^{1-2}$ Muitas famílias não são adequadamente preparadas para a alta hospitalar e para o cuidado domiciliar do RNPTBP, o que pode resultar em aumento do estresse e ansiedade da família e maiores taxas de reinternação..$^{3-4}$

Após o nascimento do RNPTBP, os pais passam por uma jornada importante na unidade neonatal, antes de chegar ao domicílio. A complexidade desta varia de acordo com o grau de prematuridade e dos problemas que cada bebê enfrenta. O ambiente da unidade neonatal apresenta muitos estressores e a educação preparatória dos pais pode ajudá-los a se sentirem prontos para a alta hospitalar. Contudo, ao mesmo tempo, pode ser um desafio para a equipe multidisciplinar. ${ }^{5}$

Com objetivo de facilitar esse processo e preparar os pais para o cuidado do bebê pré-termo em domicílio, o governo brasileiro tem proposto estratégias como o MC. Esse método preconiza o contato pele a pele, precoce, entre a mãe e o RNPTBP, de forma crescente e pelo tempo que ambos entenderem ser prazeroso e suficiente, permitindo maior participação dos pais no cuidado ao seu recém-nascido (RN). O MC foi instituído como Política Pública em 2000, a partir da publicação da 
3 | Cañedo MC, Nunes CB, Gaiva MAM, Vieira ACG, Schultz IL

norma técnica que reúne diretrizes de atenção ao RN hospitalizado em unidades neonatais. ${ }^{6}$

No Brasil, o MC é desenvolvido em três etapas. A primeira inicia na gestação de alto-risco, no parto e nascimento e na internação do RN na Unidade de Terapia Intensiva Neonatal (UTIN) e/ou na Unidade de Cuidados Intermediários Neonatal Convencional (UCINCo). A segunda é realizada na Unidade de Cuidados Intermediários Neonatal Canguru (UCINCa), onde o RN passa a maior parte do tempo em contato pele a pele com seus pais, além de receber estímulo quanto ao aleitamento materno (AM). Na terceira, após a alta hospitalar, o RNPTBP permanece com acompanhamento compartilhado pela equipe do hospital e a da Atenção Primária à Saúde (APS). ${ }^{6}$

A terceira etapa do MC estava vinculada apenas à equipe hospitalar até o bebê atingir 2.500 gramas, mas foi estendida e a APS passou a ter papéis específicos para receber e acompanhar, em parceria com a atenção especializada, os RNPTBP nas Unidades Básicas de Saúde (UBS) com as equipes da Estratégia de Saúde da Família (ESF), incluindo as visitas domiciliares e o apoio matricial dos Núcleos de Apoio à Saúde da Família (NASF). ${ }^{7}$ Desse modo, cabem às equipes de saúde, tanto do hospital como da APS, garantir uma transição segura e a realização de cuidados adequados aos bebês após a alta. ${ }^{8-9}$

Diante das indicações e benefícios do MC, além das necessidades dos RNPTBP, é indispensável que esses bebês sejam acompanhados pela equipe de saúde depois da alta da unidade neonatal. No entanto, a alta hospitalar e a transição do cuidado dos RN ainda são etapas críticas da assistência, quando se vislumbram a continuidade e a integralidade do cuidado, pois as atividades desenvolvidas estão focadas no (re)estabelecimento das condições fisiológicas do bebê, sem avaliar suas demais necessidades e de sua família. ${ }^{7}$

A escolha de se estudar a aplicação do MC no ambiente domiciliar é justificada pelos seguintes fatores: a relevância desse cuidado para o atendimento das necessidades do pré-termo e da família após a alta hospitalar, a importância de conhecer a prática domiciliar do método e os aspectos que influenciam a sua realização, e a necessidade de verificar se a hospitalização e as orientações oferecidas proporcionam um cuidado seguro aos bebês pré-termos no domicílio. ${ }^{4}$ 
“Vou para casa. E agora?” A difícil arte do Método Canguru no domicílio | 4 Ademais, a maioria dos estudos produzidos sobre o método enfoca os benefícios de sua aplicação no ambiente hospitalar, sendo pouco explorada a experiência das famílias/pais na sua implementação no domicílio, juntamente com o acompanhamento ambulatorial, que corresponde à terceira etapa do método no Brasil.4,10

Considerando que o MC ultrapassa o espaço da unidade neonatal e é realizado no próprio ambiente familiar, este estudo partiu da seguinte questão de pesquisa: Qual a experiência dos pais na aplicação do MC no domicílio? O objetivo, portanto, foi conhecer a experiência dos pais na aplicação do MC no domicílio.

\section{Método}

O estudo é de abordagem qualitativa, desenvolvido em um hospital público, em Campo Grande, capital de Mato Grosso do Sul (MS). Esse hospital possui 320 leitos vinculados ao Sistema Único de Saúde (SUS), sendo 10 leitos de Unidade de Terapia Intensiva Neonatal (UTIN), 20 de Unidade de Cuidados Intensivo Neonatal Convencional (UCINCo) e cinco de Unidade de Cuidados Intensivo Neonatal Canguru (UCINCa). Além disso, é habilitado como referência estadual para o MC e credenciado como Iniciativa Hospital Amigo da Criança (IHAC).

Participaram da pesquisa pais e mães que vivenciaram a experiência de ter seus filhos prétermos e/ou baixo peso hospitalizados na UCINCa e integraram todas as etapas do MC. Os critérios de inclusão foram pais e mães, independentes da faixa etária, residentes na capital ou no interior do estado, que participaram de todas as etapas do MC. Foram excluídos do estudo mães e pais cujo endereço a pesquisadora não localizou registrado no prontuário para realizar a visita domiciliar. Essa visita foi realizada sete dias após a alta hospitalar do bebê para observar a prática da Posição Canguru (PC), do aleitamento materno exclusivo (AME) e os cuidados prestados ao bebê baseados no MC. As pesquisadoras realizaram contato prévio pessoalmente com os pais para convidá-los a participar da pesquisa. Não houve recusas durante a captação dos participantes.

A investigação contou com a participação de 12 mães e três pais, totalizando 15 participantes. 
5 | Cañedo MC, Nunes CB, Gaiva MAM, Vieira ACG, Schultz IL

O pequeno número de pais é justificado porque, nessa unidade, o pai só acompanha os filhos em caso de gemelaridade e na ausência da mãe. Os demais têm livre acesso à unidade, mas não permanecem em tempo integral. O número de pessoas entrevistadas foi definido a partir do momento em que estas forneceram dados em quantidade e qualidade suficientes para responder ao objetivo do estudo. ${ }^{11}$

A coleta de dados ocorreu de março a dezembro de 2016 por entrevista semiestruturada, no domicílio das famílias, em local reservado e com a presença apenas do entrevistado, ou no ambulatório, quando os pais estavam participando da terceira etapa do método, em horário e dia escolhidos por eles. As entrevistas foram conduzidas pela pesquisadora responsável pelo estudo, que era enfermeira da unidade neonatal, a partir de roteiro contendo dados de identificação e a seguinte questão-guia: “Conte-me como está sendo a experiência de aplicar o MC em casa”. As entrevistas foram gravadas com a anuência dos participantes e posteriormente transcritas.

Para o tratamento do material coletado, foi utilizada a técnica de análise de conteúdo temática, ${ }^{11}$ composta por três etapas interligadas: pré-análise, que consistiu na escolha dos documentos a serem avaliados e na retomada dos objetivos da pesquisa; exploração do material transcrito com leitura em profundidade dos diálogos, o que possibilitou captar os núcleos de sentido e classificar os achados em categorias empíricas; e tratamento dos resultados obtidos e interpretação dos dados brutos, submetidos a análises. A partir desse ponto, realizaram-se interpretações, inter-relacionando-as com o referencial teórico da Política Nacional de Atenção Humanizada ao Recém-Nascido - Método Canguru e da literatura científica nacional e internacional sobre a temática. ${ }^{5-7}$

A pesquisa foi aprovada pelo Comitê de Ética em Pesquisa com Seres Humanos da Universidade Federal de Mato Grosso do Sul, com o protocolo CAAE no. 51279715.6.0000.0021, Parecer n. ${ }^{-}$1.371.216 aprovado em 16/12/2015, seguindo todos os preceitos éticos previstos nas Resoluções 466/2012 - 510/2016 - 580/2018, do Ministério da Saúde. Os participantes do estudo leram e assinaram o Termo de Consentimento Livre e Esclarecido (TCLE). Os pais e os responsáveis pelas mães adolescentes foram informados sobre a pesquisa, e os que concordaram com a participação, 
“Vou para casa. E agora?” A difícil arte do Método Canguru no domicílio | 6 assinaram o TCLE, sendo que as adolescentes assinaram o Termo de Assentimento Livre e Esclarecido. Essa investigação não contou com a participação de nenhum pai adolescente. Para preservar a identidade dos participantes, os relatos foram identificados como mãe ou pai e o número da entrevista subsequente (Mãe 1 e Pai 1, por exemplo).

\section{Resultados}

As mães participantes tinham idade entre 16 e 43 anos, todas residindo com o companheiro. Quanto à escolaridade, uma delas tinha o ensino fundamental incompleto; sete concluíram o ensino fundamental; duas, o ensino médio; duas, ensino superior. No que se refere a trabalho, seis tinham vínculo empregatício - duas empregadas domésticas, uma professora de história, uma recepcionista em um escritório de advocacia, uma operadora de montagem em uma fábrica de calçados e uma auxiliar de serviços gerais em um Centro de Educação Infantil (CEINF). A idade dos pais variou de 20 a 53 anos e o nível de escolaridade dos três foi o ensino fundamental completo. No momento das entrevistas, dois deles estavam desempregados e um era autônomo.

Do total de mães participantes, onze submeteram-se à cesariana devido a complicações maternas que levaram ao sofrimento fetal, e uma foi submetida ao parto vaginal. Seis mães eram primíparas e as outras tiveram dois ou mais partos, sendo que uma delas já havia tido parto prematuro. Quanto às causas dos nascimentos prematuros, um foi decorrente da presença de oligodramnio; um por Síndrome de Hellp, dois por Descolamento Prematuro de Placenta (DPP); cinco por Doença Hipertensiva Específica da Gestação (DHEG), dois por Trabalho de Parto Prematuro (TPP) e um por Bolsa Rota.

Devido a seis partos gemelares, este estudo contou com a participação de 18 bebês. O tempo de hospitalização variou de 15 a 115 dias; dos 18 pré-termos participantes, três foram classificados como pré-termo extremo ( $<28$ semanas), cinco como muito pré-termo (28 semanas a $<32$ semanas), seis como pré-termo moderado (32 a <34 semanas) e quatro pré-termo tardio (34 a $<37$ semanas). ${ }^{12}$

A partir dos dados obtidos nas entrevistas, a experiência dos pais na terceira etapa do MC foi 
7 | Cañedo MC, Nunes CB, Gaiva MAM, Vieira ACG, Schultz IL

agrupada em quatro núcleos temáticos: adaptação dos pais para os cuidados ao pré-termo no domicílio, aplicação da PC após a alta hospitalar, vantagens da PC no domicílio, e suporte da consulta ambulatorial na terceira etapa do MC.

\section{Adaptação dos pais para os cuidados ao pré-termo no domicílio}

O movimento de sair do hospital e ir para casa gera sentimentos de alegria nos pais dos RNPTBP, mas também traz medo e dúvidas quanto à capacidade de cuidar do filho. As rotinas das unidades neonatais, às quais os pais foram submetidos durante o longo período de hospitalização dos filhos, os acompanham em ambiente domiciliar, como se observa nos depoimentos a seguir:

[...] eu acho que aqui [em casa] eu preciso pesar a fralda. Aí eu falo: Cadê a balança? Fico até perdida. (Mãe 8)

Faço praticamente a mesma coisa. Então eu continuo dando mamá nos mesmos horários da UTI [Unidade de Terapia Intensiva], a troca de fralda, porque, querendo ou não, aqui eu posso ficar mais com ele, não tem que colocar ele no bercinho. Banho, todos os dias, nos mesmos horários do hospital[...]. (Mãe 3)

A ida para casa com o filho prematuro exige mudanças e adaptações na vida da família, mas os pais seguem as orientações recebidas no momento da alta hospitalar:

Eu pensava: como que vai ser em casa? Como que eu vou falar para as pessoas, que não pode pegar a criança? As pessoas que vieram visitar já viram como que era, a gente chegava e falava. Aí, a equipe reforçava também. Então as pessoas falavam: então, é verdade, não é enjoeira [exigência] da mãe, não é a mãe que está falando que não pode pegar [...]. Estamos sem sair de casa, sem ir para canto nenhum, a gente tem essa limitação, eu falei assim: como que eu não vou ao mercado? A gente precisa tanto ir ao mercado, no entanto, eu fui ao mercado e ele ficou no carro com o meu marido. Consegui fazer as minhas coisas, tudo dando certo, porque lá na hora a gente leva umas broncas das doutoras [risos]: vocês querem voltar para cá? Não![risos]. Então, a gente pega e faz tudo certo. (Mãe 10)

[...] Em casa, se chorar, dá mamá que para, mas não é assim, tem que dar mamá no horário. (Pai 3)

Uma preocupação de um pai, após a alta do hospital, é manter a saúde das filhas prematuras, 
“Vou para casa. E agora?” A difícil arte do Método Canguru no domicílio | 8 o que demanda cuidados no ambiente domiciliar:

[...] difícil é manter elas saudáveis. Eu levanto de madrugada, fico acordado, como agora, você está vendo? Eu não dormi à noite, mas é muito bom e é fácil. (Pai 2)

Percebe-se a segurança da mãe nos cuidados prestados as filhas após a alta hospitalar da unidade neonatal:

Eu tenho agora caminhos para lidar com elas que eu não tive com os outros, desde segurar elas, de pegar elas no colo, que elas não vão quebrar; isso foi lá que me ensinaram [...] eu ia fazer tudo errado, eu ia dar banho em excesso, elas iam chorar, ter cólicas, eu não ia saber o que fazer, eu ia dar remédio, mas não tem essa necessidade com a massagem do bebê, elas conseguem se aliviar sem precisar dar um remédio, que é o melhor para a criança. (Mãe 12)

Os participantes deste estudo mantiveram no domicílio as rotinas estabelecidas e os aprendizados adquiridos durante a hospitalização sobre os cuidados com o filho.

\section{Aplicação da Posição Canguru após a alta hospitalar}

Nos depoimentos, as mães relatam como desenvolvem o contato pele a pele no domicílio:

Aqui em casa eu tentei com lençol, só que parece que não é a mesma coisa que o de lá [hospital]. Eu só fico grudada com ele, assim, direto, coloco as perninhas dele e até para assistir TV, essas coisas, ele fica na Posição Canguru. (Mãe 10)

Lá em casa ele fica bastante coladinho em mim. Apesar de que a gente não amarra nada, mas ele fica bastante coladinho em mim. [...] ele[pai] pega assim, amarra um pano e deixa-a. Ou senão, ele pega um casaco e fecha, assim, o casaco e ele segura embaixo. E ela fica. Dorme com ele assim. (Mãe 8)

Em casa é mais no colo [...] eu coloco eles aqui juntinho do peito e apoio [...] dormem, eu deixo mais ou menos duas horas deitados em cima de mim. (Mãe 6)

Eu não tenho a faixa, então a gente amarra um pano e eu coloco as duas. Mas dá para fazer em casa, sim. Você pega um lençol e amarra nas gurias e apertam elas como se elas estivessem dentro de uma barriga. Não pode deixar muito frouxo senão ela começa a espernear e sai do canguru. E aí ela pode vazar por baixo. Primeiro de tudo, deixa a neném se encolher primeiro e depois você amarra. Ou você levanta o pezinho dela, porque, se você deixar o pezinho dela, você pode apertar e da maneira que você aperta a faixa, você 
9 | Cañedo MC, Nunes CB, Gaiva MAM, Vieira ACG, Schultz IL

pode até estar machucando a perninha dela e deixa só o pescocinho, vê se no tronco dela você não vai apertar muito também. (Pai 2)

[...] Só colocando elas no peito. Eu tenho o canguru (faixa), mas nunca usei. (Mãe 11)

O depoimento materno retrata como a família adapta o contato pele a pele de uma maneira que lhe seja prazerosa:

Aqui eu faço, eu a coloco em mim e meu marido coloca nele, então nós ficamos bastante com ela, como se estivesse no canguru do hospital. Amarradinha, mas não está. Fica no peito, mas não está amarradinha, é o Método Canguru [...]. Até na cama, ela está deitada, ela está reclamando, aí eu coloco ela aqui, ela acalma e dorme. [...] Eu não faço do mesmo jeito que no hospital, só de pele a pele, mas eu coloco, em mim. Eu amarro a faixa, ou então eu a coloco do jeito que ela estava aqui agora, deitadinha para dormir. Eu faço bastante [...]. (Mãe 7)

A mãe revela que tem medo de realizar o contato pele a pele em casa, com o uso da faixa:

Eu tenho medo. Não faço, eu tenho medo dela cair, sei lá, de escapar, da faixa desamarrar e ela cair no chão. Então, eu fico com muito medo. (Mãe 7)

Percebe-se, nos depoimentos, que outros membros da família têm a oportunidade de executar a PC no domicílio:

Eu e ele [pai] fazemos a Posição Canguru; ele adora fazer. Ele fala: olha que bonitinho, parece que elas estão dentro da minha barriga. Eu falei: agora, você está se sentindo o próprio grávido? Ele falou: estou! Aqui em casa os dois fazem Método Canguru com elas. É muito importante para a gente e para elas também. (Mãe 12)

Eu estou aplicando, pelo menos, umas quatro a cinco horas por dia. Eu fico bem com ela no colo, eu e minha mãe, principalmente, a gente faz o tempo todo. Eu amarro com medo dela cair assim. [...] Com lençol, com lençol, é o que eu tenho. (Mãe 4)

É só segurar o pescocinho, a minha filha faz, o meu marido faz, todo mundo só pega eles nessa posição, eles gostam, eles não gostam de ficar deitados, eles não estão mais na fase de recém-nascido. (Mãe 9)

A família realizou o contato pele a pele com o RNPTBP após a alta hospitalar de uma maneira prazerosa tanto para eles quanto para o bebê. 
“Vou para casa. E agora?” A difícil arte do Método Canguru no domicílio | 10

\section{Vantagens da Posição Canguru no domicílio}

Em seu relato, a mãe revela os benefícios da PC realizada no domicílio, a qual consiste, para ela, na melhor posição para manter a criança:

É a melhor posição que tem para a criança. Você não vai deixar as crianças deitadas, elas não são bonequinhas, eles são agitados, então a melhor posição que tem para eles é essa; ajuda na cólica para acalmar a barriguinha, como você pôr para arrotar, põe e eles não querem ficar deitados; estão se desenvolvendo e essa posição ajuda muito[...]. (Mãe 9)

Além disso, uma das mães destaca que a PC auxilia na execução dos afazeres no domicílio:

Todo mundo que ia me visitar queria saber o que era esse Canguru [risos]. Como assim, Canguru? E todo mundo achou muito legal, até o dia que eu fiquei lá para dobrar as roupinhas dele eu falei: gente, isso dá até para gente lavar louça [risos]. Só não dá para fazer coisa quente porque senão vai esquentar a criança, mas é um processo que você não tem que correr para ver, se a criança caiu, ou aconteceu isso. Não, 'tá ali, com você todo o tempo, você está assistindo $T V$, você pode fazer um monte de coisas. (Mãe 10)

Outro auxílio é que a PC também facilita os cuidados dos pais aos filhos gemelares:

Se eu estou com uma segurada no canguru, 'tá confortável, eu consigo até cuidar da outra. Então eu acho que, para a mãe, o Método Canguru é bem melhor, acalma o neném, tem como ela cuidar. (Pai 2)

Os depoimentos das mães também destacam como uma das vantagens da PC o fortalecimento do vínculo entre mães e filho:

Em casa comecei a fazer Posição Canguru, elas começaram a ganhar peso [...] eu já aprendi a lidar com as duas ao mesmo tempo, a amamentar as duas, que daí elas também ficam mais unidas, porque eu consigo dar amor para as duas na amamentação. (Mãe 12)

[...] por causa da criança e nós lá juntos, cria esse amor que fica tão grudado, assim que nem eu falei: eu vou ter o bebê, mas eu vou voltar a trabalhar. Mas agora não, eu tenho dúvidas se eu vou voltar a trabalhar. Porque a gente ficou tão junto, não que eu não tenha ficado assim com os outros, mas você fica tão junto, tão grudado, que não quero me separar dele. (Mãe 10)

As mães também expressam o quanto é prazeroso para elas e para os filhos a realização da PC após a alta hospitalar:

[...] O Método Canguru aproxima mais a filha da gente e aproximou bastante 
11 | Cañedo MC, Nunes CB, Gaiva MAM, Vieira ACG, Schultz IL

porque, quando eu pego as gurias, é diferente. Quando a minha mãe pega, elas choram mais. Quando eu pego, sei lá, é diferente, elas ficam quietinhas. (Mãe 8)

Eu gostei. É bom ter tido essa experiência; eu ainda gosto e ela gosta de fazer. Então, é maravilhoso. (Mãe 7)

Os pais relatam que realizam o contato pele a pele com o objetivo de tranquilizar os filhos:

Eu a ponho, às vezes, ela 'tá querendo chorar, desinquieta, eu coloco ela aqui, assim [mostra], e fico com ela deitada. Ela fica quietinha, ela dorme, ela gosta de ficar. (Mãe 1)

Elas estão inquietas, é canguru nelas!(Pai 2)

Até na cama, ela está deitada, ela 'tá reclamando, reclamando, aí eu coloco ela aqui [sobre o peito], ela acalma e dorme [...]. (Mãe 7)

Para os participantes da pesquisa, o contato pele a pele favorece o ganho de peso para o RNPTBP, auxilia na amamentação e faz bem tanto para o bebê quanto para os pais:

[...] E ficar com elas pele a pele para elas ganharem peso, ficarem fortes; a amamentação também é muito importante para elas, para o crescimento delas. (Mãe 5)

A Posição Canguru é muito agradável tanto para a mãe quanto para o bebê e faz um bem danado[faz muito bem]. (Mãe 9)

Os pais aderiram à ideia de continuar o contato pele a pele no domicílio e conseguem ver benefícios de sua prática para os bebês e para a família.

\section{Suporte da consulta ambulatorial na terceira etapa do MC}

As consultas de terceira etapa e de seguimento auxiliam os pais a entenderem os cuidados que precisam ter com os filhos no domicílio:

Você sai e você aprendeu certas coisas, automaticamente, com as coisas da casa a gente vai deixando de fazer uma coisa ou outra, mas com o acompanhamento você sabe se está ganhando peso, se não está ganhando peso, o que você está fazendo de errado, o que você pode fazer para melhorar. Então eu achei muito importante[...]. (Mãe 12)

Os pais que realizaram as consultas de enfermagem e médica na terceira etapa do MC valorizaram a importância desses acompanhamentos.

O acompanhamento da terceira etapa: ela não ganhou peso, só que ela não 
“Vou para casa. E agora?” A difícil arte do Método Canguru no domicílio| 12 perdeu o peso, ela manteve. Para mim ela tinha engordado, mas ela não estava engordando, que foi quando a enfermeira falou: vamos pesar ela de novo? Fiquei preocupada. Quando chegaram a médica e a fonoaudióloga, primeiro pensamento: vão me internar de novo. Eu já olhei para o meu marido: vai buscar as roupas [risos]. Aí, ela falou: não, a gente vai fazer assim, assado. Então é aquela segurança, a gente fica com uma segurança, eu não vejo a hora de ir lá pesar elas para ver se está tudo bem, para ver se as duas pegaram peso. Podia ter esse acompanhamento do Método Canguru até os dois anos [risos], não só até 2.500 gramas deveria ser até dois anos, porque daí você já tem uma tranquilidade, sabe que toda semana você vai estar ali, que você vai ver o acompanhamento, o crescimento, tudinho, se tiver algo de errado tem um monte de profissionais para te socorrer, te orientar ali, podia ser até dois anos, não podia ser até dois anos o Método Canguru?[risos]. (Mãe 12)

Viemos duas vezes na consulta com a enfermeira na terceira etapa, eu gostei, pois é muito minuciosa. (Pai 1)

Por outro lado, ao mesmo tempo em que a mãe expressa tranquilidade pela acessibilidade do ambulatório do hospital, relata sua insegurança quanto ao atendimento prestado pela APS no caso de o bebê adoecer:

[...] ele está tão bem! Ele está gordinho. E as doutoras passando lá todo dia de manhã, a gente tira as dúvidas, eu saí de lá, mas elas falaram: qualquer coisa que precisar, pode vir aqui. A gente tem essa segurança, pensa: como que eu vou ao posto com esse pedacinho de gente? E quando chegar lá será que eles vão saber? A gente fica insegura e aí a gente sai tendo esse apoio deles. E, assim, tem um carinho com a gente. Eu gostei muito. (Mãe 10)

Ontem, eu estava conversando com a minha mãe. Eu falei: se eu não tivesse com acompanhamento, eu não ia saber que a Lorena [nome fictício] não estava conseguindo pegar direito o peito. Porque, para mim, ela estava mamando e engordando, na minha visão. Mas, por causa do acompanhamento, eu vi que não estava. Eu falei: pera aí, tem alguma coisa errada! Se não houvesse esse acompanhamento, se tivesse que ir ao posto de 15 em 15 dias ou uma vez por mês, vixe! [...] daqui um mês o que ia acontecer? Eu não ia saber como que ela estava, que perdeu gramas e a olho nu a gente não enxerga. A gente não está vendo, quando eu fosse ver, ela já ia ter perdido muito mais [...]. (Mãe 12)

A mãe queixa-se de que a APS deveria preparar as gestantes de risco para um parto prematuro desde o pré-natal: 
13 | Cañedo MC, Nunes CB, Gaiva MAM, Vieira ACG, Schultz IL

Hoje, eu sei o que é o Método Canguru e que começa antes de nascer o bebê, a mãe grávida, com problemas, tudo, teria que ter essa parte e não tive, eu não tive todos esses cuidados, eu não sei se os postos de saúde estão preparados para encaminhar essas grávidas de risco para um atendimento mais humanizado, mas eu não tive isso. (Mãe 4)

O pai relata com entusiasmo e com alegria as conquistas da filha observadas nas consultas de seguimento, realizadas pela fisioterapeuta e terapeuta ocupacional, no hospital do estudo:

E ela falou que está bem, é como se ela tivesse nascido há um mês. Já deu uma adiantada, graças a Deus, 'tá respondendo a todas as coisas que fazem para ela: massagem, teste no ouvido, teste no olho [...]. Nós fomos ao hospital esses dias, a doutora colocou um objeto para ela ficar olhando, ela ficava prestando atenção. (Pai 3)

Entretanto uma das mães revela que teve dificuldades em levar a filha para o acompanhamento ambulatorial da terceira etapa do MC:

Não fomos à consulta, porque eu não consegui arranjar dinheiro para pagar o ônibus. (Mãe 7)

Também houve relato que evidenciou as dificuldades que as famílias enfrentam para atender às necessidades de atendimento de saúde dos filhos após a alta do hospital:

Era de noite, o postinho estava fechado, aí eu o levei na farmácia para fazer inalação, por causa do nariz dele que estava chiando, fui por conta própria, aí tive que ficar fazendo todos os dias. (Mãe 2)

Também foram observadas dificuldades em realizar o acompanhamento ambulatorial, depois da alta hospitalar, das três mães que moravam no interior do estado, devido à centralização do cuidado ao pré-termo na capital e nas grandes cidades. Destas, duas mães retornaram com dificuldades às consultas da terceira etapa e aos acompanhamentos ambulatoriais com os especialistas, sendo que uma delas permaneceu na capital até a alta da terceira etapa do MC, para só então retornar à sua cidade de origem.

\section{Discussão}

Este estudo evidenciou que os pais mantiveram a PC no domicílio. Apesar de cada família desenvolvê-la de forma diferente, não deixaram de realizá-la. Também conseguiram adaptar-se à 
“Vou para casa. E agora?” A difícil arte do Método Canguru no domicílio | 14 nova rotina de cuidados com a chegada do filho em casa e relataram satisfação com as consultas da terceira etapa e de seguimento realizadas no hospital. No entanto, um bebê não conseguiu retornar às consultas por dificuldades financeiras, demonstrando a importância de as consultas serem compartilhadas com a APS.

O vínculo criado entre mãe e filho pré-termo durante a hospitalização é frágil, em decorrência possivelmente da apreensão materna quanto à sobrevivência do RNPTBP e 2 à falta de oportunidades de interação entre eles. ${ }^{13}$ Uma pesquisa realizada na Suécia, com 13 genitoras de bebês pré-termo de duas UTINs, evidenciou que elas desejam ficar próximas dos RN durante a hospitalização e valorizam o contato pele a pele. ${ }^{14} \mathrm{Um}$ estudo 2 realizado em dois hospitais centrais no Malawi mostrou que as mães de pré-termo preferem PC aos cuidados prestados a eles na incubadora. ${ }^{15}$ Além disso, quando o profissional de saúde utiliza estratégias de acolhimento e amorosidade no trato com a mulher, tais atitudes podem favorecer para que ela se considere importante na recuperação do pré-termo, desde a sua primeira visita à UTIN. Desse modo, sentirse-á competente e confiante, conseguindo manter a sua autonomia no cuidado quando estiver em domicílio. ${ }^{16}$ Essa confiança e autonomia nos cuidados também foram observadas nesta investigação.

A continuidade da PC no domicílio auxilia no vínculo, que foi prejudicado durante a hospitalização, entre os pais e o bebê pré-termo, melhorando o controle térmico e o desenvolvimento neurocomportamental e psicoafetivo do RNPTBP, estimulando o AM e possibilitando maior segurança dos pais nos cuidados com o filho. ${ }^{6}$ Esse aspecto também foi identificado na presente pesquisa, pois alguns pais relataram que, com a evolução clínica da criança e a melhora em seu crescimento e desenvolvimento, o vínculo e a confiança na realização dos cuidados com o filho foram fortalecidos.

Um trabalho realizado com 10 mães que tiveram seus filhos pré-termos hospitalizados em uma unidade neonatal da região nordeste do Brasil demonstrou que a vivência materna, durante o MC no ambiente domiciliar, é permeada por novidades relacionadas ao cuidado ao RNPTBP, reforçando a importância da oferta de orientações claras e objetivas no decorrer da hospitalização, a 
15 | Cañedo MC, Nunes CB, Gaiva MAM, Vieira ACG, Schultz IL

fim de que ocorra a continuidade do método após a alta. ${ }^{9}$ Pesquisa com 20 casais de pais de RNPTBP, desenvolvida em dois momentos, antes e após da alta dos bebês da unidade neonatal, evidenciou as seguintes estratégias para facilitar a experiência da hospitalização e da alta: melhorar a comunicação entre os pais e a equipe de saúde; promover o contato destes com a equipe multidisciplinar; identificar as necessidades dos progenitores e facilitar o seu envolvimento nos cuidados com o filho de acordo com as necessidades individuais de cada família. ${ }^{5}$

Sob essa perspectiva, uma pesquisa que analisou o desenvolvimento de um protocolo de alta para RNPTBP, com a participação da mãe durante a hospitalização do bebê, apontou oito temáticas que devem ser contempladas durante o preparo para a alta: cuidados de higiene e conforto do bebê; amamentação; acompanhamento do crescimento; higiene das mãos; cuidados específicos com o RN; cuidados no domicílio; evolução clínica; e rotinas da assistência. ${ }^{17}$ Outro estudo ressaltou que as orientações para a alta devem estar relacionadas com o contato pele a pele, cuidados higiênicos e com a pele do RN e atenção aos sinais de alerta, como alterações respiratórias. ${ }^{8}$ Um protocolo de alta foi proposto em outro trabalho, contendo orientações sobre alimentação, banho, cuidados com a pele e sinais de alerta, ${ }^{18}$ aspectos estes reafirmados como as principais dúvidas dos familiares quanto aos cuidados aos RN. ${ }^{19}$

Além das temáticas, é fundamental discutir como essas orientações são executadas, considerando o caráter processual da alta. Desse modo, é importante que os profissionais utilizem abordagens educativas dialógicas de modo a garantir o exercício da autonomia da família na aprendizagem para o cuidado domiciliar. Outra tática é a utilização de cartilhas com orientações sobre os cuidados com bebês pré-termos nas unidades neonatais, para que a família se sinta mais segura frente aos cuidados no hospital e no domicílio. ${ }^{20}$

Ainda em relação ao preparo dos pais para a alta hospitalar, pesquisadores ressaltam a importância do enfermeiro como integrante da equipe de saúde para avaliar em quais aspectos do cuidado a mãe do RNPTBP necessita de mais apoio e orientação dos serviços de saúde, pois esse reforço pode melhorar a confiança e a autonomia delas quanto aos cuidados com o filho no domicílio. ${ }^{21}$ A tímida participação dos pais nos cuidados e nas discussões da equipe se deve ao papel 
“Vou para casa. E agora?” A difícil arte do Método Canguru no domicílio | 16 de coadjuvante nos cuidados prestados ao RNPTBP durante a hospitalização. Assim, para que eles saibam cuidar do filho no domicílio, é preciso que sejam orientados e apoiados de modo integral.

Todos os pais participantes deste estudo relataram a importância do contato pele a pele no domicílio para os RNPTBP e mantiveram a prática após a alta, situação diferente da observada em investigação conduzida em João Pessoa, Paraíba (PB), com 10 mães que participaram do MC durante a hospitalização do filho. Destas, três não deram continuidade à PC em casa e, dentre os motivos alegados para a não realização da posição, está o pouco incentivo dado pelos profissionais para o contato pele a pele no ambiente hospitalar. ${ }^{9}$ Nessa mesma pesquisa, foi possível verificar o fortalecimento do vínculo mãe-filho dentre aquelas que realizaram a posição e a importância do apoio familiar. Nenhuma mãe relatou ter recebido apoio da equipe da APS, revelando falha no acompanhamento do RNPTBP no domicílio, ${ }^{9}$ tal como observado nesta pesquisa.

Quanto ao acompanhamento pós-alta do pré-termo, investigação realizada no ambulatório de uma maternidade de João Pessoa, PB, cujo objetivo foi investigar os sentimentos das mães em voltar para casa e também as suas percepções sobre o atendimento prestado pelos profissionais da terceira etapa do MC, retratou sua satisfação com o atendimento prestado nesse ambulatório. No entanto, nenhuma participante mencionou ter recebido a visita domiciliar da equipe da APS após a alta hospitalar do filho pré-termo. Desse modo, o estudo reforçou a importância da formação de vínculo entre os profissionais de saúde da maternidade e os da APS, por meio da participação dos últimos em reuniões periódicas realizadas na maternidade e do livre acesso destes aos RNPTBP durante a hospitalização. ${ }^{22}$ Essa situação também foi observada nas entrevistas dos participantes da presente pesquisa, evidenciando o não compartilhamento da terceira etapa do MC com a APS, demostrando que o cuidado ainda é incipiente.

A articulação entre a unidade neonatal e a APS deve ser iniciada na hospitalização, com o intuito de conhecer as condições clínicas do RN e assegurar a continuidade da atenção após a alta da unidade neonatal. ${ }^{23}$ Esse compartilhamento pode ocorrer de diversas formas, como demonstrou o estudo qualitativo desenvolvido com 18 mães de crianças egressas de uma unidade neonatal de Foz 
17 | Cañedo MC, Nunes CB, Gaiva MAM, Vieira ACG, Schultz IL

do Iguaçu, Paraná (PR). Os resultados mostraram que as oportunidades de orientações em visita domiciliar e por suporte telefônico são pertinentes para promover o cuidado do RNPTBP e detectar as condições iminentes. Nesses contatos, as dúvidas sobre os cuidados em domicílio foram sanadas; além disso, foi possível observar situações de vulnerabilidade nos acompanhamentos especializados e de descontinuidade no seguimento do crescimento e desenvolvimento do RNPTBP. ${ }^{24}$

Referente ao conhecimento dos pais sobre o MC, estudo realizado com 113 mães com filhos hospitalizados na Unidade Canguru nos hospitais de Bwaila e no hospital central de Zomba, no Malawi, revelou um alto nível de conhecimento sobre os benefícios do MC, mas que $84 \%$ não conheciam os serviços antes da hospitalização do filho na unidade. ${ }^{15}$ Esse dado corrobora os achados desta pesquisa, visto que uma das mães afirmou não ter sido informada sobre o MC durante o pré-natal de alto risco, conforme prevê a estratégia.

Estudo que analisou o perfil dos $\mathrm{RN}$ atendidos na consulta de enfermagem em um ambulatório de seguimento do RN de risco, em hospital de referência ao MC de Brasília, Distrito Federal, mostrou que esse atendimento melhorou tanto o AME quanto o ganho de peso ponderal dessas crianças. $^{25} \mathrm{Na}$ presente pesquisa, os pais, além de reconhecerem a importância e os beneficios do método, também elogiaram as consultas da terceira etapa do MC e as de seguimento realizadas pela equipe multiprofissional no hospital.

Sabe-se que a participação dos profissionais da APS no acompanhamento pós-alta dos RNPTBP ainda é tímida, como mostrou a pesquisa realizada com 31 profissionais de saúde que atuavam na APS no município de Joinville, Santa Catarina, evidenciando que consideravam o atendimento ao RNPTBP um desafio para o qual se sentiam desamparados e despreparados. São sugeridas ações de divulgação, capacitação e sensibilização sobre o MC para que ocorra a efetivação da terceira etapa do método após a alta da unidade neonatal, considerando o princípio da integralidade no cuidado. ${ }^{26}$

É imprescindível que as equipes dos hospitais, em especial dos programas de seguimento aos RNPTBP e da APS, trabalhem juntas e proporcionem o acompanhamento adequado do RN depois da alta hospitalar, por meio do apoio à amamentação, observação do ganho de peso, tratamento de 
intercorrências e avaliação de reinternações. Ademais, até que essas crianças alcancem o peso de 2.500 gramas, os profissionais desses serviços devem apoiar suas famílias. ${ }^{6}$

As evidências científicas mostram que quanto menor a idade gestacional do RNPTBP e menor o seu peso de nascimento, maiores serão suas vulnerabilidades fisiológicas, metabólicas e psicológicas, o que traz preocupações com seu prognóstico. ${ }^{6}$ Essa observação foi abordada em pesquisa que avaliou o perfil de RN de risco atendidos em ambulatório de seguimento, em que os bebês que necessitaram de mais consultas de enfermagem na terceira etapa do MC foram aqueles com menor ganho ponderal e os com menor idade gestacional. ${ }^{27}$

Dessa forma, é importante fortalecer a continuidade do cuidado após a alta hospitalar do RNPTBP, para que o bebê alcance o crescimento e desenvolvimento adequados. Pesquisa realizada com 18 profissionais da Secretaria Municipal de Saúde, de um município no estado do PR, mostrou descompassos quando se analisaram os encaminhamentos da criança pré-termo e/ou baixo peso após a alta, pois muitas delas ficaram desamparadas, sem conseguir atendimento e, quando conseguiram, receberam apenas os cuidados básicos, a pesagem e a vacinação. ${ }^{27} \mathrm{O}$ atendimento prestado ao RNPTBP pelas unidades da APS foi uma preocupação manifestada por mães participantes desta pesquisa, especialmente pelo fato de as consultas na APS serem mensais e não semanais, como ocorre na terceira etapa do MC.

A prematuridade é uma das principais causas de mortalidade infantil e a realização do contato pele a pele, após a alta hospitalar, pode reduzir esse risco. Todavia, o acompanhamento do pré-termo e sua família precisa ser efetivo, seja por meio de consultas, seja em visitas domiciliares e educação em saúde, ações que têm impacto positivo na prestação de cuidados seguros e eficientes aos pré-termos. ${ }^{22}$ Para a efetivação e a continuidade do cuidado ao RNPTBP após a alta, há necessidade de melhorias no acesso aos serviços e um maior apoio dos profissionais de saúde. ${ }^{28}$

Percebe-se que os profissionais da APS desconhecem os benefícios do MC, pois costumam apenas aumentar as consultas prestadas ao RNPTBP e sua família na terceira etapa do método, mas geralmente não orientam os pais sobre a continuidade da PC no domicílio. ${ }^{4}$ Já com relação aos 
19 | Cañedo MC, Nunes CB, Gaiva MAM, Vieira ACG, Schultz IL

gestores de saúde, um estudo realizado na Indonésia revelou que eram conhecidas as vantagens dessa técnica, incluindo a termorregulação, o ganho de peso, a formação de vínculo entre os pais e o filho e a redução de recursos humanos. ${ }^{29}$

Além de mostrar a falta de articulação entre o hospital e a APS no atendimento pós-alta do RNPTBP, os resultados deste estudo também evidenciaram que algumas famílias enfrentam dificuldades para comparecer às consultas no ambulatório do hospital de origem, em especial por falta de recursos financeiros. Essa questão também foi apontada por pesquisa realizada em João Pessoa, $\mathrm{PB}$, que mostrou que, dentre as dificuldades sentidas pelos pais para levar os filhos às consultas ambulatoriais, estavam a distância entre a casa do RNPTBP e os serviços de saúde, além da demanda dos outros filhos, falta de tempo e limitações financeiras. ${ }^{9}$ Os autores sugerem que sejam realizadas ações de divulgação e de capacitação das equipes de saúde, e também a pactuação entre os diferentes níveis de atenção à saúde, para que a terceira etapa do MC seja efetiva na APS. ${ }^{26}$

Uma situação observada no estado de MS (que também ocorre em outros estados brasileiros) é que as unidades neonatais estão localizadas, na grande maioria, nas capitais, o que leva as mães dos RNPTBP a aguardarem em residências de familiares, amigos ou em casas de apoio até a alta da terceira etapa do MC. Assim, essa família acaba recebendo cuidados nas UBS próximas a esses locais e não naquelas contíguas à sua residência. Por isso, o contato com os agentes comunitários de saúde e com os demais profissionais de saúde da UBS de sua origem só vai ocorrer muito tempo depois da alta hospitalar. ${ }^{7}$ Além dessas dificuldades apontadas, a efetivação da terceira etapa do MC, no âmbito hospitalar, enfrenta outros desafios; dentre eles: a desospitalização e os cuidados no domicílio, e a referência e contrarreferência, que é frágil entre os serviços. ${ }^{10}$ Portanto, faz-se necessária a implementação de um modelo de comunicação interinstitucional que inclua todos os serviços de saúde com apoio dos gestores de saúde. ${ }^{30}$

Como limitação da pesquisa, destaca-se que os dados sobre a percepção de mães e pais quanto ao desenvolvimento do MC em domicílio são referentes a um único hospital. Além disso, o número reduzido de pais entrevistados em relação às mães pode ser um fator limitante em relação 
“Vou para casa. E agora?” A difícil arte do Método Canguru no domicílio | 20 aos dados obtidos. Todavia, as dificuldades vivenciadas pelos pais de RNPTBP, após a alta hospitalar, são importantes e poderão subsidiar gestores e profissionais de saúde na implementação de mudanças na atenção a essa população, visto que o hospital de estudo é credenciado para o MC e a IHAC. Sugere-se o prosseguimento de novas pesquisas envolvendo outros hospitais da capital e do interior do estado, bem como maior participação do pai, além de profissionais de saúde, tanto da APS como da atenção terciária, o que pode ampliar a compreensão do fenômeno investigado.

\section{Conclusão}

O relato dos pais mostrou que todos aplicavam diariamente a PC no domicílio; mesmo diante dos desafios diários dos cuidados após a alta hospitalar, eles revelaram ter uma acepção clara sobre a importância e os benefícios da PC e de sua capacidade de impactar na qualidade do cuidado oferecido ao filho pré-termo. Esses resultados permitem inferir que o hospital investigado possuiu ações em saúde amplas e qualificadas no preparo dos pais dos RNPTBP para a alta hospitalar.

O conhecimento sobre como o MC é vivido e percebido pelos pais após a alta hospitalar revelou fragilidades na articulação da terceira etapa do método entre o serviço investigado e a APS, constituindo um desafio a ser enfrentado pela instituição, sobretudo em relação às famílias dos RNPTBP que vivem no interior do estado e aquelas com problemas sociais e econômicos. Todavia, os resultados deste estudo podem contribuir com a enfermagem tendo em vista a importância do profissional enfermeiro como integrante da equipe multiprofissional, uma vez que é ele que avalia quais aspectos do cuidado aos RNPTBP os familiares necessitam em termos de apoio e orientação, tanto antes da alta hospitalar da unidade neonatal como também no domicílio. Além disso, são nas visitas domiciliares e nas consultas de terceira etapa do MC compartilhadas entre o hospital de origem e a APS que as necessidades das famílias podem ser detectadas.

\section{Referências}

1. Raiskila S, Axelin A, Toome L, Caballero S, Tandberg BS, Montirosso R, et al. Parents' presence and parent-infant closeness in 11 neonatal intensive care units in six European countries vary between and within 
the countries. Acta Pediatr. 2017;106(6):878-88. doi: 10.1111/apa.13798

2. Serlachius A, Hames J, Juth V, Garton D, Rowley S, Petrie KJ, et al. Parental experiences of family-centred care from admission to discharge in the neonatal intensive care unit. J Pediatr Child Health. 2018;54(11):122733. doi: $10.1111 /$ jpc.14063

3. Adama EA, Bayes S, Sundin D. Parents' experiences of caring for preterm infants after discharge from neonatal intensive care unit: a meta-synthesis of the literature. J Neonatal Nurs. 2016;22(1):27-51. doi: 10.1016/j.jnn.2015.07.006

4. Reichert APS, Soares AR, Bezerra ICS, Guedes ATA, Pedrosa RKB, Vieira DS. Terceira etapa do método canguru: experiência de mães e profissionais da atenção primária. Esc Anna Nery Rev Enferm. 2021;25(1):e20200077. doi: 10.1590/2177-9465-ean-2020-0077

5. Aydon L, Hauck Y, Murdoch J, Siu D, Sharp M. Transition from hospital to home: parents' perception of their preparation and readiness for discharge with their preterm infant. J Clin Nurs. 2018;27(1-2):269-77. doi: 10.1111/jocn.13883

6. Ministério da Saúde (BR), Secretaria de Atenção à Saúde, Departamento de Ações Programáticas Estratégicas. Atenção humanizada ao recém-nascido: Método Canguru: manual da terceira etapa do Método Canguru na Atenção Básica. Brasília (DF): Ministério da Saúde; 2018 [acesso em 2020 nov 02]. Disponível em: http://bvsms.saude.gov.br/bvs/publicacoes/manual_terceira_etapa_metodo_canguru.pdf

7. Lamy ZC, Silva M, Morch DS. Cuidado compartilhado entre a atenção hospitalar e a atenção básica. In: Sanches MTC, Costa R, Azevedo VMGO, Morsch DS, Lamy ZC. Método Canguru no Brasil: 15 anos de política pública. São Paulo: Instituto de Saúde; 2015. (Temas em Saúde Coletiva; 19).

8. Sales IMM, Santos JDM, Rocha SS, Gouveia MTO, Carvalho NAR. Contribuições da equipe enfermagem na segunda etapa do Método Canguru: implicações para a alta hospitalar do recém-nascido. Esc Anna Nery Rev Enferm. 2018;22(4):e20180149. doi: 10.1590/2177-9465-EAN-2018-0149

9. Reichert APS, Soares AR, Bezerra ICS, Dias TKC, Guedes ATA, Vieira DS. Vivência materna com o método canguru no domicílio. REME Rev Min Enferm. 2020;24:e-1295. doi: 10.5935/1415-2762.20200024

10. Aires LCP, Koch C, Santos EKA, Costa R, Mendes JS, Medeiros GMS. Método canguru: estudo documental de teses e dissertações da enfermagem brasileira (2000-2017). Rev Bras Enferm. 2020;73(2):e201805981. doi: 10.1590/0034-7167-2018-0598

11. Minayo MCS. O desafio do conhecimento: pesquisa qualitativa em saúde. 14ª ed. São Paulo: Hucitec; 2014.

12. Sociedade Brasileira de Pediatria. Nota Técnica 2019 - Prematuridade. Rio de Janeiro: Sociedade Brasileira de Pediatria; 2019 [acesso em 2021 jan 21]. Disponível em: https://www.sbp.com.br/fileadmin/user_upload/Nota_Tecnica_2019_Prematuridade.pdf

13. Barroso ML, Pontes AL, Rolim KMC. Consequências da prematuridade no estabelecimento do vínculo afetivo entre mãe adolescente e recém-nascido. Rev Rene. 2015;16(2):168-75. doi: 10.15253/21756783.2015000200005

14. Norén J, Nyqvist KH, Rubertsson C, Blomqvist YT. Becoming a mother - Mothers' experience of Kangaroo Mother Care. Sex Reprod Healthc. 2018;16:181-85. doi: 10.1016/j.srhc.2018.04.005 
“Vou para casa. E agora?” A difícil arte do Método Canguru no domicílio | 22

15. Chisenga JZ, Chalanda M, Ngwale M. Kangaroo Mother Care: a review of mothers' experiences at Bwaila hospital and Zomba Central hospital (Malawi). Midwifery. 2015;31(2):305-15. doi: 10.1016/j.midw.2014.04.008

16. Heck GMM, Lucca HC, Costa R, Junges CF, Santos SV, Borck M. Compreensão do sentimento materno na vivência no Método Canguru. Rev Enferm UFSM. 2016;6(1):71-83. doi: 10.5902/2179769218083

17. Veronez M, Higarashi IH. Protocolo para a alta de bebê pré-termo: subsídios para a construção de uma proposta. Rev Enferm UERJ. 2016;24(3):7505. doi: 10.12957/reuerj.2016.7505

18. Silva FVR, Gomes TO, Marta CB, Araujo MC, Braga ES. Preparo dos pais de recém-nascido pré-termo para alta hospitalar: proposta de um protocolo. Rev Pesqui Cuid Fundam. 2020;12:386-92. doi: 10.9789/21755361.rpcfo.v12.8264

19. Santos AST, Góes FGB, Ledo BC, Silva LF, Bastos MPC, Silva MA. Tecnologia educativa sobre cuidados domiciliares com o recém-nascido de baixo risco. Rev Enferm UERJ. 2020;28:e44488. doi: 10.12957/reuerj.2020.44488

20. Silva IOAM, Aredes NDA, Bicalho MB, Delácio NCB, Mazzo LDL, Fonseca LMM. Cartilha sobre o prematuro como tecnologia educacional para família: estudo quase experimental. Acta Paul Enferm. 2018;31(4):334-41. doi: 10.1590/1982-0194201800048

21. Feitosa MR, Gubert FA, Tomé MABG, Pinheiro MTM, Neves CS, Benevides JL. Primary health care follow-up visits: investigation of care continuity of preterm newborns from a kangaroo-mother care unit. Int Arch Med. 2017;10(32). doi: 10.3823/2302

22. Dias TKC, Guedes ATA, Batista TNL, Vieira DS, Albuquerque TM, Santos NCC, et al. Kangaroo mother care: feelings and perceptions of mothers in stage three. Int Arch Med. 2016;9(7). doi: 10.3823/1878

23. Ministério da Saúde (BR). Atenção humanizada ao recém-nascido: Método Canguru: Manual técnico. Brasília (DF): Ministério da Saúde; 2017 [acesso 2020 nov 02]. Disponível em: http://bvsms.saude.gov.br/bvs/publicacoes/atencao_humanizada_metodo_canguru_manual_3ed.pdf

24. Silva RMM, Zilly A, Nonose ERS, Fonseca LMM, Mello DF. Oportunidades de cuidados à criança prematura: visita domiciliar e suporte telefônico. Rev Latinoam Enferm. 2020;28:e3308. doi: 10.1590/15188345.3520 .3308

25. Beleza LO, Ribeiro LM, Paula RAP, Guarda LEDA, Vieira GB, Costa KSF. Perfil de recém-nascidos de risco atendidos por enfermeiros em seguimento ambulatorial: estudo de coorte retrospectiva. Rev Latinoam Enferm. 2019;27:e3113. doi: 10.1590/1518-8345.2301.3113

26. Aires LCP, Santos EKA, Costa R, Bork M, Custódio ZAO. Baby follow-up in primary care: interface with the third stage of the kangaroo method. Rev Gaúcha Enferm. 2015;36(Spec No):224-32. doi: 10.1590/19831447.2015.esp.56805

27. Klossoswski DG, Godói VC, Xavier CR, Fujinaga CI. Assistência integral ao recém-nascido prematuro: implicações das práticas e da política pública. Rev CEFAC. 2016;18(1):137-50. doi: 10.1590/1982021620161814515

28. Oliveira JA, Braga PP, Gomes IF, Ribeiro SS, Carvalho PCT, Silva AF. Continuidade do cuidado na prematuridade. Saúde (Santa Maria). 2019;45(1)1-11. doi: 10.5902/2236583423912 
29. Pratomo H, Amelia T, Nurlin F, Adisasmita AC. Knowledge and perceptions of kangaroo mother care among health providers: a qualitative study. Clin Exp Pediatr. 2020;63(11):433-7. doi: 10.3345/cep.2018.06506

30. Aires LCP, Santos EKA, Bruggemann OM, Backes MTS, Costa R. Referência e contrarreferência do bebê egresso da unidade neonatal no sistema de saúde: percepção de profissionais de saúde da Atenção Primária. Esc Anna Nery Rev Enferm [Internet]. 2017 [cited 2020 Nov 02];21(2):e20170028. Available from: https://www.scielo.br/scielo.php?pid=S1414-81452017000200201\&script=sci_abstract\&tlng=pt

Editora Científica Chefe: Cristiane Cardoso de Paula

Editora associada: Graciela Dutra Sehnem

\section{Autor correspondente}

Mayara Carolina Cañedo

E-mail: maycarolina@hotmail.com

Endereço: Av. Eng. Lutero Lopes, 36 - Conj. Aero Rancho, Campo Grande - MS, Brasil. CEP: 79084-180.

\section{Contribuições de autoria}

\section{1 - Mayara Carolina Cañedo}

Colaborou com a concepção da pesquisa; análise e interpretação dos dados coletados; redação do artigo e revisão com participação crítica e intelectual do mesmo.

\section{2 - Cristina Brandt Nunes}

Colaborou com a concepção da pesquisa; análise e interpretação dos dados coletados; redação do artigo e revisão com participação crítica e intelectual do mesmo.

\section{3 - Maria Aparecida Munhoz Gaiva}

Colaborou com a análise e interpretação dos dados coletados; redação do artigo; revisão final com participação crítica e intelectual do mesmo.

\section{4 - Ana Cláudia Garcia Vieira}

Colaborou com a análise e interpretação dos dados coletados; redação do artigo; revisão final com participação crítica e intelectual do mesmo.

\section{5 - Iluska Lopes Schultz}

Colaborou com a redação do artigo; revisão final com participação crítica e intelectual do mesmo.

\section{Como citar este artigo}

Cañedo MC, Nunes CB, Gaiva MAM, Vieira ACG, Schultz IL. "I'm going home. And now?" The difficult art of the Kangaroo Method at home. Rev. Enferm. UFSM. 2021 [Accessed in: Year Month Day]; vol.11 e52: 1-23. DOI: https://doi.org/10.5902/2179769263253 